\title{
Springer
}

\section{A STANDARD SET OF VALUE-BASED PATIENT-CENTERED OUTCOMES FOR PANCREATIC CARCINOMA: AN INTERNATIONAL DELPHI SURVEY}

\begin{tabular}{|c|c|}
\hline Journal: & Annals of Surgical Oncology \\
\hline Manuscript ID & Draft \\
\hline Manuscript Type: & Original Article \\
\hline $\begin{array}{r}\text { Date Submitted by the } \\
\text { Author: }\end{array}$ & $\mathrm{n} / \mathrm{a}$ \\
\hline Complete List of Authors: & $\begin{array}{l}\text { Cherkaoui, Zineb; CHU Strasbourg, Digestive and Endocrine Surgery } \\
\text { Unit, Nouvel Hôpital Civil } \\
\text { González, Cristians ; Institute of Image-Guided Surgery (IHU } \\
\text { Strasbourg), Université de Strasbourg, Strasbourg, 67091, France } \\
\text { Wakabayashi, Taiga; Research Institute Against Digestive Cancer (IRCAD } \\
\text { ) } \\
\text { Delattre, Bastien ; Integrated Health Solutions (IHS), Medtronic France, } \\
\text { Boulogne-Billancourt, 92100, France } \\
\text { Léost, Elodie; Integrated Health Solutions (IHS), Medtronic France, } \\
\text { Boulogne-Billancourt, 92100, France } \\
\text { Serra, Sébastien ; CHU Strasbourg } \\
\text { Huppertz, Jérôme; CHU Strasbourg } \\
\text { Klein, Francine; CHU Strasbourg } \\
\text { Stéphan , Marie; CHU Strasbourg } \\
\text { Meyer, Jean-Michel; CISS Alsace (Collectif Inter associatif Sur la Santé) } \\
\text { Strasbourg, France } \\
\text { Schaff, Alain ; CHU Strasbourg, Digestive and Endocrine Surgery Unit, } \\
\text { Nouvel Hôpital Civil } \\
\text { Martinis, Elisa; CHU Strasbourg, Digestive and Endocrine Surgery Unit, } \\
\text { Nouvel Hôpital Civil } \\
\text { Bangoura, Elena; CHU Strasbourg, Digestive and Endocrine Surgery Unit, } \\
\text { Nouvel Hôpital Civil } \\
\text { Kieffer, Sophie; CHU Strasbourg, Digestive and Endocrine Surgery Unit, } \\
\text { Nouvel Hôpital Civil } \\
\text { Blanes-Brice, Sophie; CHU Strasbourg, Digestive and Endocrine Surgery } \\
\text { Unit, Nouvel Hôpital Civil } \\
\text { Haddad, Elham; CHU Strasbourg, Oncology Unit } \\
\text { Deguio, Gabrielle; Groupe Hospitalier Saint Vincent, Strasbourg, France } \\
\text { Felli, Emanuele; Nouvel Hôpital Civil, General, Digestive, and Endocrine } \\
\text { Surgery } \\
\text { Pernot, Sophie; Institute of Image-Guided Surgery (IHU Strasbourg), } \\
\text { Université de Strasbourg, Strasbourg, 67091, France } \\
\text { Marescaux, Jacques; IRCAD-IHU University of Strasbourg, General, } \\
\text { Digestive and Endocrine Surgery } \\
\text { Mutter, Didier; CHU Strasbourg, Digestive and Endocrine Surgery Unit, } \\
\text { Nouvel Hôpital Civil; Institute of Image-Guided Surgery (IHU } \\
\text { Strasbourg), Université de Strasbourg, Strasbourg, 67091, France; } \\
\text { Research Institute Against Digestive Cancer (IRCAD ) } \\
\text { Lugiez, Constance; Integrated Health Solutions (IHS), Medtronic France, } \\
\text { Boulogne-Billancourt, 92100, France }\end{array}$ \\
\hline
\end{tabular}


Pessaux, Patrick; CHU Strasbourg, Digestive and Endocrine Surgery Unit, Nouvel Hôpital Civil; Institute of Image-Guided Surgery (IHU Strasbourg), Université de Strasbourg, Strasbourg, 67091, France; Research Institute Against Digestive Cancer (IRCAD )

\section{SCHOLARONE ${ }^{m}$ Manuscripts}




\section{A STANDARD SET OF VALUE-BASED PATIENT-CENTERED OUTCOMES FOR PANCREATIC CARCINOMA: AN INTERNATIONAL DELPHI SURVEY}

Zineb Cherkaoui ${ }^{1}$, Cristians González ${ }^{2}$, Taiga Wakabayashi ${ }^{3}$, Bastien Delattre ${ }^{4}$, Elodie Léost ${ }^{5}$, Sébastien Serra ${ }^{6}$, Jerôme Huppertz ${ }^{7}$, Francine Klein ${ }^{8}$, Marie Stéphan ${ }^{9}$, Jean-Michel Meyer ${ }^{10}$, Alain Schaff ${ }^{11}$, Elisa Martinis ${ }^{12}$, Elena Bangoura ${ }^{13}$, Sophie Kieffer ${ }^{14}$, Sophie Blanès ${ }^{15}$, Elham Haddad $^{16}$, Gabrielle De Guio ${ }^{17}$, Emanuele Felli ${ }^{18}$, Sophie Pernot ${ }^{19}$, Jacques Marescaux ${ }^{20}$, Didier Mutter $^{21}$, Constance Lugiez ${ }^{22}$, Patrick Pessaux ${ }^{23}$, IHU-VBHC Working Group.

\section{Degrees and affiliations:}

${ }^{1} \mathrm{MD}$,

Institute of Image-Guided Surgery (IHU Strasbourg), Université de Strasbourg, Strasbourg, 67091, France

Digestive and Endocrine Surgery Unit, Nouvel Hôpital Civil, Hôpitaux Universitaires de Strasbourg, Université de Strasbourg, Strasbourg, France

SSPC (Simplification of Surgical Patient Care), UR UPJV 7518, University of Picardie Jules Verne, Amiens, France

email: zineb.cherkaoui@,chru-strasbourg.fr

${ }^{2} \mathrm{MD}$,

Institute of Image-Guided Surgery (IHU Strasbourg), Université de Strasbourg, Strasbourg, 67091, France

Digestive and Endocrine Surgery Unit, Nouvel Hôpital Civil, Hôpitaux Universitaires de Strasbourg, Université de Strasbourg, Strasbourg, France

email: cristians.gonzalez@ihu-strasbourg.eu

${ }^{3} \mathrm{MD}$, 
VBHC Pancreas Set

Research Institute Against Digestive Cancer (IRCAD ), Strasbourg, 67091, France

email: taiga.wakabayashi@me.com

${ }^{4}$ Consultant,

Integrated Health Solutions (IHS), Medtronic France, Boulogne-Billancourt, 92100, France

email: bastien.delattre@gmail.com

${ }^{5}$ Patient-pathway Coordinator,

Integrated Health Solutions (IHS), Medtronic France, Boulogne-Billancourt, 92100, France

email: elodie.leost@medtronic.com

${ }^{6} \mathrm{MD}$

Hôpitaux Universitaires de Strasbourg, Nouvel Hôpital Civil, 67091, Strasbourg, France

email: sebastian.serra@,chru-strasbourg.fr

${ }^{7} \mathrm{MD}$,

Hôpitaux Universitaires de Strasbourg, Nouvel Hôpital Civil, 67091, Strasbourg, France

email: jeromehuppertz@gmail.com

${ }^{8}$ Head nurse,

Digestive and Endocrine Surgery Unit, Nouvel Hôpital Civil, Hôpitaux Universitaires de Strasbourg, Université de Strasbourg, Strasbourg, France

email: francine.klein@chru-strasbourg.fr

${ }^{9}$ Nurse,

Digestive and Endocrine Surgery Unit, Nouvel Hôpital Civil, Hôpitaux Universitaires de Strasbourg, Université de Strasbourg, Strasbourg, France

email: marie.stephan@chru-strasbourg.fr

${ }^{10}$ Patient representative, President of CISS Alsace,

CISS Alsace (Collectif Inter associatif Sur la Santé) Strasbourg, France

email: jean-michel.meyer@,cushabitat.fr

Page 2 sur 14 
VBHC Pancreas Set

11 Patient,

Digestive and Endocrine Surgery Unit, Nouvel Hôpital Civil, Hôpitaux Universitaires de Strasbourg, Université de Strasbourg, Strasbourg, France

email: none

12 Dietician,

Digestive and Endocrine Surgery Unit, Nouvel Hôpital Civil, Hôpitaux Universitaires de Strasbourg, Université de Strasbourg, Strasbourg, France

email: elisa.martinis@,chru-strasbourg.fr

${ }^{13}$ Caregiver,

Digestive and Endocrine Surgery Unit, Nouvel Hôpital Civil, Hôpitaux Universitaires de Strasbourg, Université de Strasbourg, Strasbourg, France

email: elena.bangoura@chru-strasbourg.fr

14 Nurse,

Digestive and Endocrine Surgery Unit, Nouvel Hôpital Civil, Hôpitaux Universitaires de Strasbourg, Université de Strasbourg, Strasbourg, France

email: sophie.kieffer@chru-strasbourg.fr

${ }^{15}$ Secretary,

Digestive and Endocrine Surgery Unit, Nouvel Hôpital Civil, Hôpitaux Universitaires de Strasbourg, Université de Strasbourg, Strasbourg, France

email: sophie.blanes-brice@chru-strasbourg.fr

${ }^{16}$ Nurse,

Oncology Unit, Hôpitaux Universitaires de Strasbourg, Nouvel Hôpital Civil, 67091, Strasbourg, France

email: elham.haddad@chru-strasbourg.fr

17 MD, 
VBHC Pancreas Set

Groupe Hospitalier Saint Vincent, Strasbourg, France

email: gabrielle.deguio@gmail.com

$18 \mathrm{MD}$

Digestive and Endocrine Surgery Unit, Nouvel Hôpital Civil, Hôpitaux Universitaires de Strasbourg, Université de Strasbourg, Strasbourg, France

email: emanuele.felli@,chru-strasbourg.fr

${ }^{19}$ Preclinical \& innovation project manager,

Institute of Image-Guided Surgery (IHU Strasbourg), Université de Strasbourg, Strasbourg, 67091, France

email: sophie.pernot@ihu-strasbourg.eu

${ }^{20}$ MD, FACS, Hon FRCS, Hon JSES, Hon FASA, President of IRCAD, Chairman of the Institute of Image-Guided Surgery, WebSurg Editor-in-Chief,

Institute of Image-Guided Surgery (IHU Strasbourg), Université de Strasbourg, Strasbourg, 67091, France

Research Institute Against Digestive Cancer (IRCAD ), Strasbourg, 67091, France email: jacques.marescaux@ircad.fr

${ }^{21} \mathrm{MD}, \mathrm{PhD}$,

Digestive and Endocrine Surgery Unit, Nouvel Hôpital Civil, Hôpitaux Universitaires de Strasbourg, Université de Strasbourg, Strasbourg, France

Institute of Image-Guided Surgery (IHU Strasbourg), Université de Strasbourg, Strasbourg, 67091, France

Research Institute Against Digestive Cancer (IRCAD ), Strasbourg, 67091, FRANCE

email: didier.mutter@,chru-strasbourg.fr

22 IHS Program Director,

Integrated Health Solutions (IHS), Medtronic France, Boulogne-Billancourt, 92100, France 
VBHC Pancreas Set

email: constance.lugiez@medtronic.com

${ }^{23} \mathrm{MD}, \mathrm{PhD}$,

Digestive and Endocrine Surgery Unit, Nouvel Hôpital Civil, Hôpitaux Universitaires de Strasbourg, Université de Strasbourg, Strasbourg, France

Hepatobiliary and Pancreatic Surgical Unit, Nouvel Hôpital Civil (NHC), Strasbourg, France Institute of Image-Guided Surgery (IHU Strasbourg), Université de Strasbourg, Strasbourg, 67091, France

Research Institute Against Digestive Cancer (IRCAD ), Strasbourg, 67091, France

Unité Inserm UMR_S1110, Institut de Recherche sur les Maladies Virales et Hépatiques, Strasbourg

Corresponding author, email: patrick.pessaux@,chru-strasbourg.fr

Tel: +33 369551286

Fax: +33 369551745

Page 5 sur 14 


\section{Background:}

Global health systems are shifting toward value-based health care (VBHC) to improve patient outcomes in the face of rising health care costs. The challenge is to identify standardized outcome measurements that allow the optimal monitoring and comparison of the quality of care, in order to optimize medical practices and patient pathways. A common outcomes definition is required, including medical results (CROMs, Clinical Reported Outcomes Measurements) and quality of life components that matter most to patients (PROMs, Patient Reported Outcomes Measurements), particularly important for severe pathologies with short life expectancy like pancreatic cancer. The aim of this work was to create standardized metrics that could be used for outcomes analysis of pancreatic cancer care.

\section{Methods:}

A multidisciplinary working group (WG) was assembled. A systematic review was conducted to collect the most used outcomes in pancreatic cancers clinical studies. A total of 570 studies published in the last ten years were reviewed; 3370 outcomes, including CROMs, and PROMs, were listed and prioritized. The WG reached a consensus on key outcomes, proposed groupings for CROMs and PROMs, identified existing questionnaires which could be used for PROMs collection and set the timeline for data collection. To refine and validate the final outcomes set an international external committee completed a Delphi process (two rounds both for CROMS and PROMs).

\section{Results:}

After the systematic literature review, the WG selected 102 outcomes (92 CROMs/10 PROMs) to submit to the international Delphi vote committee. In total, 89 outcomes $(78 \mathrm{CROMs} / 11$ PROMs) were retained. For PROMs the WG and the international external committee chose a validated questionnaire, the Fact-Hep, that covers all of the 11 selected PROMs.

\section{Conclusions:}


A standardized set of outcome measures that need to be validated through international health outcome comparisons and quality-of-care assessments was built. Pilot projects are underway to test and optimize the approach in real-life conditions.

\section{INTRODUCTION:}

Pancreatic cancer is the second most common digestive cancer in the United States, where approximately 44,000 new cases occur each year. In Europe, pancreatic cancer accounts for $2.8 \%$ of cancers among men and $3.2 \%$ among women, making it the sixth most common cancer [1]. Based on GLOBOCAN 2012 estimates, pancreatic cancer is the cause of more than 331,000 deaths per year, which represents the seventh leading cause of cancer-related deaths worldwide, with a five-year survival rate of less than $5 \%$ [2]. Despite the availability of newer and more effective chemotherapy regimens, the survival rate associated with this disease has remained consistently low.

Radical surgery is the only potential curative treatment for pancreatic cancer [3]. Despite the availability of newer and more effective chemotherapy regimens, prognosis of pancreatic cancer remains grim for most patients. Hence the importance of providing outcomes that really matter for this patient population.

Global health systems are shifting to value-based health care (VBHC) to drive better health outcomes in the face of rising care costs $[4,5]$. The challenge is to identify standardized outcome metrics that allow the optimal monitoring and comparison of the quality of care, in order to optimize medical practices and patient pathways. A common outcomes definition is required, including medical results (CROMs, Clinical Reported Outcomes Measurement) and also quality of life components that matter most to patients (PROMs, Patient Reported Outcomes Measurement). This is particularly important for severe pathologies with short life expectancy like pancreatic cancer [6]. 
Although several standardized datasets have been developed to measure both clinical and patient-oriented value-based health outcomes in the context of cancers of the breast [7], colon [8], lung [9], and prostate [10,11], standardized outcome measurement sets for pancreatic cancer are not currently available.

The aim of this work was to develop a standardized outcome measurement set that would be used in an outcomes analysis of pancreatic cancer pathways, to monitor patient quality of life and better meet patients expectations, and to identify and align on the best practices between the different care centers.

\section{MATERIALS AND METHODS:}

\section{Working Group}

A multidisciplinary working group (WG) of 20 people was assembled. The WG was composed of physicians (hepatobiliary pancreatic (HBP) surgeons, medical oncologists, gastroenterologists), paramedical personnel (nurses, dieticians, caregivers), patient, patient representative, administrative staff, and healthcare consultants. The WG was set up to prepare a Delphi process to validate the outcomes metrics set.

\section{Review of Clinical Trials and Outcomes pre-selection}

A systematic literature review of outcomes used in pancreatic cancers clinical trials was carried out by searching the clinicaltrials.gov database. Phase II, III or IV studies published in the last ten years on pancreatic cancer adult population were considered.

A total of 570 clinical studies were selected and reviewed. The studies listed 3370 outcomes, including CROMs (3168 items) and PROMs (201 items). After a first review 92 CROMs and 10 PROMs were selected by the WG (Figure 1).

\section{Outcomes Structuring}

CROMs were divided into 2 parts: 
- A baseline set with 4 categories: 1) demographic factors, 2) clinical characteristics, 3) diagnostic methodology, and 4) therapeutic strategy (Table 1).

- A follow-up set with 3 categories: 1) treatment-related complications, 2) survival and disease control indicators, 3) evidence of relapse or disease progression. The final list of outcomes is listed in Table 2.

PROMs were grouped into health domains by the WG members using a method inspired by Macefield et al. [12] and Van Rijssen et al. [13]. Quality of life (QOL) and functioning items were encompassed in 5 categories: 1) physical well-being, 2) family and social well-being, 3) emotional well-being, 4) functional well-being, and 5) current symptomatology (Table 3).

\section{Validation committee and process}

An international external validation committee (VC) was formed to complete a Delphi process to refine and validate the final set (Figure 1). The VC comprised 93 persons and included patients, HPB surgeons, radiologist, psychiatrist, oncologists, nurses, dieticians, psychologist (Table 4). The Qualtrics platform was used to create and distribute questionnaires, and 4 rounds ( 2 for CROMs, 2 for PROMs) were carried out between the $31^{\text {st }}$ of January and the $15^{\text {th }}$ of June 2018.

\section{Outcomes validation}

Questionnaires in the first two rounds focused on the validation of CROMs. Participants had to answer the following question: "Please indicate if you would like to add or exclude the following variables in the final standard set". Participants could justify their choices during the first round. Only the variables reaching a threshold set at $85 \%$ of the addition rate were retained for the final standard set; those under a threshold at $15 \%$ were not retained; those between $15 \%$ and $85 \%$ had to be voted again in the second round. In the second round, the arguments from the first round were presented to the participants, and only the variables reaching $85 \%$ were retained. 
Questionnaires in the second two rounds focused on the validation of PROMs.

In the first round, the outcomes were listed, with examples (questions extracted from existing questionnaires). The $\mathrm{VC}$ was asked to select the most relevant outcomes. Only the variables reaching a threshold set at $85 \%$ of the addition rate were retained for the final standard set; those under a threshold of $15 \%$ were not retained; those between $15 \%$ and $85 \%$ had to be voted again in the second round. In the second round, only the variables reaching $85 \%$ were retained. Participants chose the most suitable existing questionnaire in relation to their PROMs selection.

\section{Set timeline}

To finalize the deployment preparation, the WG decided to define a timeline for outcomes collection (patient record for CROMs, questionnaires for PROMs), to suit to the different care episodes.

\section{RESULTS:}

The WG defined the scope of the project as including all patients with stage I to IV invasive pancreatic cancer in accordance with the American Joint Committee of Cancer staging system, regardless of type or intent of treatment received, including those who did not receive therapy. Patients undergoing treatment with investigational agents were excluded because such studies have their own specific outcome assessments.

\section{CROMs}

Baseline items were included to allow for cross-treatment and cross-center comparison.

The demographic factors included sex, date of birth, weight, height, units of weight and height, and family history of pancreas-related cancer.

Baseline clinical factors prioritized for inclusion were the Eastern Cooperative Oncology Group (ECOG) score performance status, presence of comorbidities, and the level of alcohol and/or tobacco consumption [14]. The Charlson Comorbidity Index was selected for comorbidity 
reporting [15]. The different methodologies used to verify the diagnosis were included, as well as the date of the tests.

Several baseline diseases and tumor factors were also included: nature and date of onset of cardinal symptoms, amount of weight loss, duration of weight loss evolution, tumor location, and clinical TNM stage. The items related to the therapeutic strategy were grouped as follows: a) general strategies (multidisciplinary care, intention of treatment and type of treatment selected) and b) specific strategies (surgical treatment, radiotherapy treatment, chemotherapy treatment and the need for an approach to biliary drainage).

Follow-up items were included to monitor the trends of medical outcomes.

Treatment-related event measures focused on short-term complications of treatment, including type and severity. An algorithmic evaluation to determine severity was developed based on the grading systems of the Clavien-Dindo classification for surgical complications [16] and the Common Terminology Criteria for Adverse Events for radiation therapy and chemotherapy (Version 4.0) [17]. The causes of postsurgical complications related to pancreatic surgery (pancreatic fistula, gastroparesis, hemorrhage) were evaluated separately and classified according to their severity $[18,19,20]$. Similarly, the implementation of nutritional support and the need for new admissions were selected from the proposed variables.

The following measures were included for survival and disease control: overall survival, causespecific survival, recurrence-free survival, progression-free survival, and need for readmission. For patients receiving neoadjuvant therapy or surgery, pathological complete response and margin status were included because they would be able to serve as intermediary outcomes, proxies of survival, and short-term indicators of surgical quality.

The occurrence, method of diagnosis, date of relapse (for patients treated with curative intent) or progression (for patients treated with palliative indication) were also included in the follow- 
VBHC Pancreas Set

up variables. These events are reported as they were identified and are considered a new baseline point.

A total of $78 \mathrm{CROMs}$ were selected, with response referentials and administration timeline

(Tables $1 \& 2$ ).

\section{PROMs}

The final PROMs set (Quality Of Life, functioning, and symptom measures) are listed in Table

3.

PROMs were recommended to be collected at baseline (when the patient treatment was defined) and then 1 month after treatment, 3 months, 6 months, 9 months, 1 year, 18 months, and annually up to 10 years after treatment, where possible.

A total of 11 PROMs were selected, with a validated questionnaire, the Fact-Hep [21], for outcomes collection.

\section{DISCUSSION:}

Until now, there was no widely validated standardized outcome measures for the follow-up of patients with pancreatic cancer. Our work aimed to build an innovative metrics set, in order to improve the quality and relevancy of care for patients, to facilitate comparison of results across treatments, between health care professionals (HCP) and centers around the world, and to support the research on this disease. The outcomes measurement could allow a wider vision of the care pathway.

A standardized set of metrics is a decision-support tool for care evaluation, which allows a real dialogue between care providers and patients and a personalized treatment strategy.

A comparison among centers can help to improve the care organization and a set of outcomes measurement can contribute to the identification of care priorities essential under constrained resources. 
Last, the continuous standardized outcomes assessment using real-time data together with the integration of patient's expectations (through the results of validated PROMs) could facilitate medical innovations since it would become easier to appreciate the variations of the different indicators related to the introduction of technological or organizational innovations.

Outcomes reported by patients are becoming as important as the clinical results. A systematic review of the burden of pancreatic cancer in Europe showed that pancreatic cancer results in a $98 \%$ loss of healthy life [22]. The severity of pancreatic cancer and the limited availability of effective treatment options [3] compel the medical community to prioritize patients' experiences and outcomes over objective medical results. Patient-centered outcomes reflect patients' life experience when dealing with their disease. The collection of PROMs has been shown to improve QOL and even overall survival in the context of other types of cancer [23]. The report of the Centre Fédéral d'Expertise des Soins de Santé (Bruxelles-Belgium) implements the application of results and experiences reported by patients (PROMs/patient-reported experience measures (PREMs)) for clinical and management purposes. The report specifies the three levels that are favored through its use: a) the relationship between the patient and his/her healthcare provider, to promote shared decision-making and patient-centered care (micro level); b) healthcare facilities, to contribute to the improvement of quality of care (meso level); and c) the public-policy level, to monitor and measure the performance of national health systems (macro level) [24].

\section{Feasibility and acceptability of outcomes measurement}

A metrics set has to be accepted by all stakeholders in the care pathway. To do so, it is a matter of co-building these indicators with all actors; the patient was subsequently considered to be an "actor" of his/her pathway in the same way as the other stakeholders, taking part in the care pathway. In our strategy, this multidisciplinary and multi-professional team, with the presence of patients, patient associations, HCP in direct and long-term contact with patients, was 
VBHC Pancreas Set

respected within the working group and the international external committee. This presence highlighted patient experience and expectations beyond the medical expertise.

The metrics set has to be SMART (specific, measurable, achievable and realistic) and has to quantify the outcomes both in terms of CROMs and PROMs. Recently, the COPRAC study group established an international core set of PROMs that were selected by both patients and healthcare providers in the United States, Europe, and Asia [13]. In this study 8 categories of PROMs (general QOL, general health, physical capacity, ability to work and perform usual activities, fear of recurrence, satisfaction with services and care organization, abdominal complaints and relationship with partner or family) were included. Limit of the COPRAC study was not to define in detail each category content.

Our set aims to measure the outcomes in a valid and reliable manner and the VC considered that the most suitable questionnaire for assessing the selected PROMs and the Fact-Hep [21] was chosen. The FACT-Hep was developed in 1998 to measure health-related quality of life in patients with hepatobiliary cancers.

The WG determined a timeline for the CROMs and PROMs collection, balanced between the clinically relevant times (i.e.: new treatment needs to be tightly monitored) and pragmatic concerns faced by institutions and practices in regard to data collection (i.e.: patient's scheduled follow-up visits).

In conclusion, a standardized set of patient-centered outcome measures that need to be monitored for international health outcome comparisons and quality-of-care assessments was built for pancreatic carcinoma. The implementation of instruments that integrate the measurement of clinical parameters of treatment response and patient-reported outcomes, both in clinical research protocols and in routine medical practice, is a step forward to ensure that each patient receives the necessary and effective care in each setting and situation. 


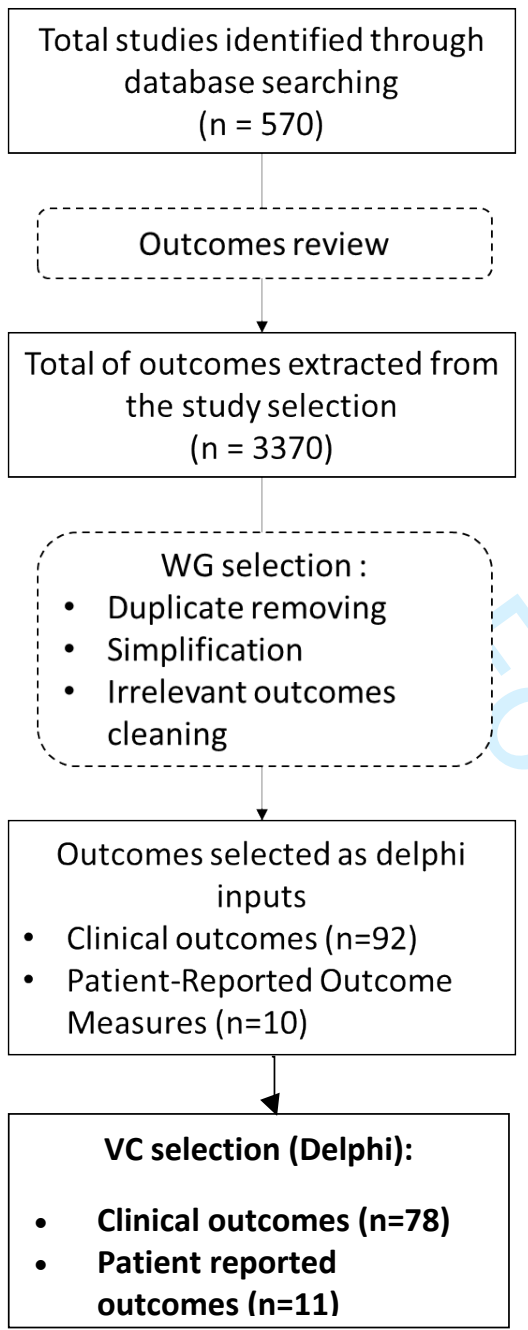

Figure 1: Systematic Outcomes Review Flow Chart

WG: Working Group

VC: Validation Committee 
VBHC Pancreas Set

Table 1

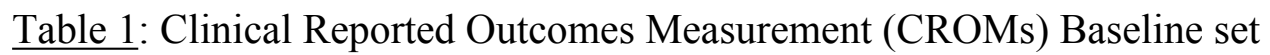

\begin{tabular}{|c|c|c|c|c|}
\hline & $\begin{array}{c}\text { PATIENT } \\
\text { POPULATION }\end{array}$ & DETAILS & $\begin{array}{c}\text { DATA } \\
\text { SOURCE }\end{array}$ & TIMELINE \\
\hline \multicolumn{5}{|l|}{ 1. DEMOGRAPHIC FACTORS } \\
\hline Sex & \multirow{5}{*}{ All patients } & Patient Sex & \multirow{2}{*}{$\begin{array}{c}\text { Administrative } \\
\text { data }\end{array}$} & \multirow{5}{*}{$\begin{array}{l}\text { Baseline } \\
\text { (u: baseline and follow } \\
\text { up) }\end{array}$} \\
\hline Age & & Date of Birth & & \\
\hline Weight $^{\mu}$ & & Unit of measurement (kg or lb) & \multirow{3}{*}{$\begin{array}{l}\text { Clinical } \\
\text { abstraction }\end{array}$} & \\
\hline Height & & Unit of measurement $(\mathrm{cm}$ or $\mathrm{ft})$ & & \\
\hline Family History of Cancer & & $\begin{array}{l}\text { First degree parent with Pancreas, } \\
\text { Breast/Ovarian, Colon, Melanoma }\end{array}$ & & \\
\hline \multicolumn{5}{|c|}{ 2. CLINICAL CHARACTERISTICS } \\
\hline \multicolumn{5}{|l|}{ Patient Characteristics } \\
\hline Score Performance $(\mathrm{ECOG})^{\mu}$ & \multirow{4}{*}{ All patients } & $\begin{array}{l}\text { Eastern Cooperative Oncology } \\
\text { Group (ECOG) Performance Status } \\
\text { [14] }\end{array}$ & \multirow{4}{*}{$\begin{array}{l}\text { Clinical } \\
\text { abstraction }\end{array}$} & \multirow{4}{*}{$\begin{array}{l}\text { Baseline } \\
\text { (u: baseline and follow- } \\
\text { up) }\end{array}$} \\
\hline Comorbidities $^{\mu}$ & & Charlon Comorbidity Index [15] & & \\
\hline Alcohol Consumption & & $\begin{array}{l}\text { Beverage-specific quantity and } \\
\text { frequency (units per day) }\end{array}$ & & \\
\hline Tobacco use & & Smoking Exposure (pack-year) & & \\
\hline \multicolumn{5}{|l|}{ Disease Characteristics } \\
\hline Cardinal Symptoms & \multirow{4}{*}{ All patients } & Onset date and nature of symptoms & \multirow{4}{*}{$\begin{array}{l}\text { Clinical } \\
\text { abstraction }\end{array}$} & \multirow{4}{*}{ 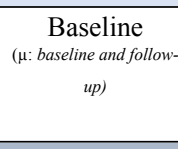 } \\
\hline Weight Loss ${ }^{\mu}$ & & Amount and time of evolution & & \\
\hline Tumor Location & & Anatomical location of the tumor & & \\
\hline cTNM Stage & & Preoperative staging of the disease & & \\
\hline \multicolumn{5}{|c|}{ 3. DIAGNOSTIC METHODOLOGY } \\
\hline CT-Scan & \multirow{4}{*}{ All patients } & \multirow{4}{*}{ Test date (if applicable) } & \multirow{4}{*}{$\begin{array}{l}\text { Administrative } \\
\text { data }\end{array}$} & \multirow{4}{*}{ Baseline } \\
\hline MRI & & & & \\
\hline Endoscopic Ultrasound & & & & \\
\hline Biopsy & & & & \\
\hline \multicolumn{5}{|l|}{ 4. THERAPEUTIC STRATEGY } \\
\hline \multicolumn{5}{|l|}{ General } \\
\hline Multidisciplinary Meeting & \multirow{3}{*}{ All patients } & Meeting date (if applicable) & \multirow{3}{*}{$\begin{array}{l}\text { Clinical } \\
\text { abstraction }\end{array}$} & \multirow{3}{*}{$\begin{array}{c}\text { Baseline } \\
+ \\
\text { Follow-up }\end{array}$} \\
\hline Intention of Treatment & & Curative or palliative intent & & \\
\hline Type of Treatment Selected & & Modality of treatment chosen & & \\
\hline Surgery & & & & \\
\hline ASA Score & & $\begin{array}{l}\text { Physical Status Classification } \\
\text { System }\end{array}$ & $\begin{array}{c}\text { Clinical } \\
\text { abstraction }\end{array}$ & \\
\hline Date of Surgery & & Specify the date of the intervention & & \\
\hline Type of Surgery & & Specify procedure performed & Surgical Report & \\
\hline Approach & & Minimally invasive or open surgery & & \\
\hline Quality of Resection & & Specify specimen margin status & & \\
\hline Standardized Pathological Report & $\begin{array}{l}\text { surgery } \\
\text { solng }\end{array}$ & $\begin{array}{l}\text { Completeness of recommended } \\
\text { parameters }\end{array}$ & $\begin{array}{l}\text { Pathological } \\
\text { Report }\end{array}$ & Follow-up \\
\hline pTNM Stage & & Postoperative staging of disease & & \\
\hline Hospitalization Length & & Admission and discharge dates & $\begin{array}{l}\text { Administrative } \\
\text { data }\end{array}$ & \\
\hline Radiotherapy & & & & \\
\hline Type & Patients receiving & & & Follow-un \\
\hline Dose (cGy) & neoadjuvant/palliative & details (if applicable) & abstraction & ronow-up \\
\hline $\begin{array}{l}\text { Duration of treatment } \\
\text { Chemotherapy }\end{array}$ & treatment & & & \\
\hline Type & Patients receiving & Start and finish date and treatment & Clinical & Follow-un \\
\hline Duration of treatment & $\begin{array}{l}\text { treatment } \\
\text { the }\end{array}$ & details (if applicable) & abstraction & \\
\hline Biliary Drainage & & & & \\
\hline Type $^{\mu}$ & All patients & Placement date and technical details & Clinical & Baseline \\
\hline Date of Treatment ${ }^{\mu}$ & & (if applicable) & abstraction & $\stackrel{+}{+}{ }^{+}$ \\
\hline
\end{tabular}


Table 2

Table 2: Clinical Reported Outcomes Measurement (CROMs) Follow-Up set

\begin{tabular}{|c|c|c|c|c|}
\hline & $\begin{array}{l}\text { PATIENT } \\
\text { POPULATION }\end{array}$ & DETAILS & $\begin{array}{l}\text { DATA } \\
\text { SOURCE }\end{array}$ & TIMELINE \\
\hline \multicolumn{5}{|c|}{ 1. TREATMENT-RELATED COMPLICATIONS } \\
\hline \multicolumn{5}{|l|}{ Surgery-Related Complications } \\
\hline Post-Surgical Complications & \multirow{5}{*}{$\begin{array}{l}\text { Patients receiving } \\
\text { surgery }\end{array}$} & $\begin{array}{l}\text { Clavien-Dido } \\
\text { classification of surgical } \\
\text { complications [16] }\end{array}$ & \multirow{5}{*}{$\begin{array}{l}\text { Clinical } \\
\text { abstraction }\end{array}$} & \multirow{5}{*}{ Follow-up } \\
\hline Pancreatic Leakage & & & & \\
\hline Gastroparesis & & $\begin{array}{l}\text { International study } \\
\text { group for pancreatic } \\
\text { surgery [18-20] }\end{array}$ & & \\
\hline Hemorrhage & & & & \\
\hline Transfusion & & $\begin{array}{l}\text { Blood transfusion } \\
\text { requirements }\end{array}$ & & \\
\hline \multicolumn{5}{|c|}{ Palliative/Neoadjuvant Treatment-Related Complications } \\
\hline Tumor Response & \multirow{2}{*}{ All patients } & $\begin{array}{l}\text { No sign of residual } \\
\text { cancer on diagnosis } \\
\text { evaluation }\end{array}$ & \multirow{2}{*}{$\begin{array}{l}\text { Clinical } \\
\text { abstraction }\end{array}$} & \multirow{2}{*}{ Follow-up } \\
\hline Undesirable Effects & & $\begin{array}{l}\text { Common terminology } \\
\text { criteria for adverse } \\
\text { events V4.03 [17] }\end{array}$ & & \\
\hline \multicolumn{5}{|l|}{ Readmissions } \\
\hline Need for Readmission & \multirow{2}{*}{ All patients } & \multirow{2}{*}{$\begin{array}{l}\text { New admission at any } \\
\text { time for any cause }\end{array}$} & \multirow{2}{*}{$\begin{array}{l}\text { Administrative } \\
\text { data }\end{array}$} & \multirow[t]{2}{*}{ Follow-up } \\
\hline Date of Readmission & & & & \\
\hline \multicolumn{5}{|c|}{ 2. SURVIVAL AND DISEASE CONTROL } \\
\hline Overall Survival & \multirow[b]{2}{*}{ All patients } & Date of death & \multirow{2}{*}{$\begin{array}{l}\text { Administrative } \\
\text { data }\end{array}$} & \multirow{6}{*}{$\begin{array}{l}\text { Long-Term Follow- } \\
\text { Up } \\
\text { (Annual follow-up } \\
\text { from the first year of } \\
\text { treatment) }\end{array}$} \\
\hline $\begin{array}{l}\text { Cause-Specific } \\
\text { Survival }\end{array}$ & & $\begin{array}{l}\text { Death attributed to } \\
\text { pancreatic cancer }\end{array}$ & & \\
\hline Recurrence-Free Survival & $\begin{array}{l}\text { Patients with } \\
\text { curative intent }\end{array}$ & $\begin{array}{l}\text { Local, regional, or distal } \\
\text { recurrence }\end{array}$ & \multirow{4}{*}{$\begin{array}{l}\text { Clinical } \\
\text { abstraction }\end{array}$} & \\
\hline Progression-Free Survival & $\begin{array}{l}\text { Patients with } \\
\text { advanced disease }\end{array}$ & Disease progression & & \\
\hline $\begin{array}{l}\text { Pathological or Clinical Complete } \\
\text { Response }\end{array}$ & $\begin{array}{l}\text { Patients receiving } \\
\text { neoadjuvant } \\
\text { treatment }\end{array}$ & $\begin{array}{l}\text { No sign of residual } \\
\text { invasive cancer of } \\
\text { resected specimen or on } \\
\text { diagnosis evaluation }\end{array}$ & & \\
\hline Need for Readmission & All patients & $\begin{array}{l}\text { Evidence of margin } \\
\text { involvement }\end{array}$ & & \\
\hline \multicolumn{5}{|c|}{ 3. RELAPSE/PROGRESSION OF THE DISEASE } \\
\hline \multicolumn{5}{|l|}{ Disease Relapse } \\
\hline Relapse Date & \multirow{2}{*}{$\begin{array}{l}\text { Patients with } \\
\text { curative intent }\end{array}$} & \multirow{2}{*}{$\begin{array}{l}\text { Onset date. Nature of } \\
\text { event. Detection Method } \\
\text { (clinical, imaging and/or } \\
\text { pathological } \\
\text { identification) }\end{array}$} & \multirow{2}{*}{$\begin{array}{l}\text { Clinical } \\
\text { abstraction }\end{array}$} & \multirow{2}{*}{ Follow-up } \\
\hline Method of Detection & & & & \\
\hline \multicolumn{5}{|l|}{ Disease Progression } \\
\hline Progression Date & \multirow{2}{*}{$\begin{array}{l}\text { Patients with } \\
\text { advanced disease }\end{array}$} & \multirow{2}{*}{$\begin{array}{l}\text { Onset date. Nature of } \\
\text { event. Detection Method } \\
\text { (clinical, imaging and/or } \\
\text { pathological } \\
\text { identification) }\end{array}$} & \multirow{2}{*}{$\begin{array}{l}\text { Clinical } \\
\text { abstraction }\end{array}$} & \multirow{2}{*}{ Follow-up } \\
\hline Method of Detection & & & & \\
\hline
\end{tabular}


Table 3: Patient Reported Outcomes Measurement (PROMs) set

\begin{tabular}{|c|c|c|c|c|}
\hline & $\begin{array}{l}\text { PATIENT } \\
\text { POPULATION }\end{array}$ & DETAILS & DATA SOURCE & TIMELINE \\
\hline \multicolumn{5}{|c|}{ 1. PHYSICAL WELL-BEING } \\
\hline Energy & \multirow{7}{*}{ All patients } & \multirow{7}{*}{$\begin{array}{l}\text { Tracked via FACT-Hep } \\
{[21]}\end{array}$} & \multirow{7}{*}{$\begin{array}{l}\text { Patient-reported } \\
\text { source }\end{array}$} & \multirow{7}{*}{$\begin{array}{l}\text { Every follow-up control } \\
\text { starting at baseline }\end{array}$} \\
\hline Nausea & & & & \\
\hline Physical autonomy & & & & \\
\hline Pain & & & & \\
\hline Treatment Side Effect & & & & \\
\hline Illness perception & & & & \\
\hline Prostration & & & & \\
\hline \multicolumn{5}{|c|}{ 2. FAMILY/SOCIAL WELL-BEING } \\
\hline Relatives support & \multirow{4}{*}{ All patients } & \multirow{4}{*}{$\begin{array}{l}\text { Tracked via FACT-Hep } \\
{[21]}\end{array}$} & \multirow{4}{*}{$\begin{array}{l}\text { Patient-reported } \\
\text { source }\end{array}$} & \multirow{4}{*}{$\begin{array}{l}\text { Every follow-up control } \\
\text { starting at baseline }\end{array}$} \\
\hline Relatives acceptance & & & & \\
\hline $\begin{array}{l}\text { Communication with } \\
\text { family and friends }\end{array}$ & & & & \\
\hline $\begin{array}{l}\text { Satisfaction with sexual } \\
\text { life }\end{array}$ & & & & \\
\hline \multicolumn{5}{|c|}{ 3. EMOTIONAL WELL-BEING } \\
\hline Sadness & \multirow{5}{*}{ All patients } & \multirow{5}{*}{$\begin{array}{l}\text { Tracked via FACT-Hep } \\
{[21]}\end{array}$} & \multirow{5}{*}{$\begin{array}{l}\text { Patient-reported } \\
\text { source }\end{array}$} & \multirow{5}{*}{$\begin{array}{l}\text { Every follow-up control } \\
\text { starting at baseline }\end{array}$} \\
\hline Coping capacities & & & & \\
\hline Hope & & & & \\
\hline Nervousness & & & & \\
\hline Fearness & & & & \\
\hline \multicolumn{5}{|c|}{ 4. FUNCTIONAL WELL-BEING } \\
\hline Fitness for work & \multirow{6}{*}{ All patients } & \multirow{6}{*}{$\begin{array}{l}\text { Tracked via FACT-Hep } \\
\text { [21] }\end{array}$} & \multirow{6}{*}{$\begin{array}{l}\text { Patient-reported } \\
\text { source }\end{array}$} & \multirow{6}{*}{$\begin{array}{l}\text { Every follow-up control } \\
\text { starting at baseline }\end{array}$} \\
\hline Work accomplishment & & & & \\
\hline Life enjoyment & & & & \\
\hline Illness acceptance & & & & \\
\hline Sleep quality & & & & \\
\hline QOL satisfaction & & & & \\
\hline \multicolumn{5}{|l|}{ 5. SYMPTOMS } \\
\hline \multicolumn{5}{|l|}{ General } \\
\hline Fatigue & \multirow{9}{*}{ All patients } & & & \\
\hline Fever & & & & \\
\hline Weight Loss & & & & \\
\hline Insomnia & & & & \\
\hline Jaundice & & Tracked via FACT-Hep & Clinical abstraction & Every follow-up control \\
\hline Itching & & {$[21]$} & $\begin{array}{l}\text { Patient-reported } \\
\text { sources }\end{array}$ & starting at baseline \\
\hline $\begin{array}{l}\text { Change of physical } \\
\text { appearance }\end{array}$ & & & sources & \\
\hline Back pain & & & & \\
\hline Dry mouth & & & & \\
\hline Gastrointestinal & & & & \\
\hline $\begin{array}{l}\text { Abdominal } \\
\text { Distension/Pain }\end{array}$ & & & & \\
\hline Dietary Restrictions & & Tracked via FACT-Hep & Patient-reported & Every follow-up control \\
\hline Nauseas and Vomiting & All patients & {$[21]$} & source & starting at baseline \\
\hline $\begin{array}{l}\text { Ability to Eat/Appetite } \\
\text { Loss }\end{array}$ & & & & \\
\hline Bowel Function & & & & \\
\hline Stool Frequency & & & & \\
\hline Diarrhea & & Tracked via FACT-Hep & Patient-reported & Every follow-up control \\
\hline Constipation & All patients & {$[21]$} & source & starting at baseline \\
\hline Fecal Continence & & & & \\
\hline
\end{tabular}




\section{VBHC Pancreas Set}

Table 4

Table 4: Composition of the Validation Committee

\begin{tabular}{|l|l|l|}
\hline Expertise & n & \% \\
\hline HBP Surgeons & 60 & $64.5 \%$ \\
\hline Patients & 8 & $8.6 \%$ \\
\hline Nurses & 8 & $8.6 \%$ \\
\hline Medical Oncologists & 8 & $8.6 \%$ \\
\hline Dieticians & 5 & $5.3 \%$ \\
\hline Psychologist & 1 & $1.1 \%$ \\
\hline General Surgeon & 1 & $1.1 \%$ \\
\hline Psychiatrist & 1 & $1.1 \%$ \\
\hline Radiologist & 1 & $1.1 \%$ \\
\hline Region & 16 & $17.2 \%$ \\
\hline Europe & $\mathbf{n}$ & 14 \\
\hline North America & 17 & $18.3 \%$ \\
\hline Asia & & $15.0 \%$ \\
\hline
\end{tabular}


VBHC Pancreas Set

References

\section{REFERENCES:}

[1] Bardou, M, Le Ray, I. Treatment of pancreatic cancer: A narrative review of costeffectiveness studies. Best Practice \& Research Clinical Gastroenterology, 2013; 27(6), 881892.

[2] Ilic M, Ilic I. Epidemiology of pancreatic cancer. World J Gastroenterol. 2016; 22(44), 9694-9705.

[3] Neuzillet C, Gaujoux S, Williet N, Bachet JB, Bauguion L, Colson Durand L, Conroy T, Dahan L, Gilabert M, Huguet F, Marthey L, Meilleroux J, de Mestier L, Napoléon B, Portales F, Sa Cunha A, Schwarz L, Taieb J, Chibaudel B, Bouché O, Hammel P; Thésaurus National de Cancérologie Digestive (TNCD); Société Nationale Française de Gastroentérologie (SNFGE); Fédération Francophone de Cancérologie Digestive (FFCD); Groupe Coopérateur multidisciplinaire en Oncologie (GERCOR); Fédération Nationale des Centres de Lutte Contre le Cancer (UNICANCER); Société Française de Chirurgie Digestive (SFCD); Société Française d'Endoscopie Digestive (SFED); Société Française de Radiothérapie Oncologique (SFRO); Association de Chirurgie Hépato-Bilio-Pancréatique et Transplantation (ACHBT); Association Française de Chirurgie (AFC). Pancreatic cancer: French clinical practice guidelines for diagnosis, treatment and follow-up (SNFGE, FFCD, GERCOR, UNICANCER, SFCD, SFED, SFRO, ACHBT, AFC). Dig Liver Dis. 2018 Dec;50(12):1257-1271

[4] Porter ME. A Strategy for Health Care Reform - Toward a Value-Based System. N Eng J Med. 2009;361(2):109-12.

[5] Pessaux P, Cherkaoui Z. Value-based healthcare: a novel approach to the evaluation of patient care. Hepatobiliary Surg Nutr. 2018 Apr;7(2):125-126. 
[6] Johansen NJ, Saunders CM. Value-Based Care in the Worldwide Battle Against Cancer. Cureus, 2017; 9(2): e1039.

[7] Ong WL, Schouwenburg MG, van Bommel AC, et al. A standard set of value-based patientcentered outcomes for breast cancer: the International Consortium for Health Outcomes Measurement (ICHOM) Initiative. Jama Oncol, 2017; 3(5):677-685.

[8] Zerillo JA, Schouwenburg MG, van Bommel ACM et al. A standard set of value-based patient- centered outcomes for colon cancer: the International Consortium for Health Outcomes Measurement (ICHOM) Initiative. JAMA Oncol. 2017;3(5):686-694.

[9] Mak KS, van Bommel AC, Stowell C, et al.: Defining a standard set of patient-centered outcomes for lung cancer. Eur Respir J. 2016, 48:852-860. 10.1183/13993003.02049-2015

[10] Martin NE, Massey L, Stowell C, et al.: Defining a standard set of patient-centered outcomes for men with localized prostate cancer. Eur Urol. 2015, 67:460-467. 10.1016/j.eururo.2014.08.075

[11] Morgans AK, van Bommel AC, Stowell C, et al.: Development of a standardized set of patient- centered outcomes for advanced prostate cancer: an international effort for a unified approach. Eur Urol. 2015, 68:891-898.

[12] Macefield RC, Jacobs M, Korfage IJ et al. Developing core outcomes sets: methods for identifying and including patient-reported outcomes (PROs). Trials. 2014; 15:49.

[13] van Rijssen LB, Gerritsen A, Henselmans I et al. Core Set of Patient-reported Outcomes in Pancreatic Cancer (COPRAC): An International Delphi Study Among Patients and Health Care Providers. AnnSurg.2017.doi:10.1097 /SLA. 0000000000002633.

[14] Oken M, Creech R, Tormey D, et al. Toxicity and response criteria of the Eastern Cooperative Oncology Group. Am J Clin Oncol. 1982; 5:649-655. 
VBHC Pancreas Set

References

[15] Charlson M, Szatrowski TP, Peterson J. Validation of a combined comorbidity index. J Clin Epidemiol. 1994; 47(11):1245-51.

[16] Clavien PA, Barkun J, de Oliveira ML et al. The Clavien-Dindo classification of surgical complications: five-year experience. Ann Surg. 2009; 250(2):187-96.

[17] National Cancer Institute. Common Terminology Criteria for Adverse Events v.4.0 (CTCAE). Available from: http:// ctep. cancer.gov/ protocolDevelopment/ electronic applications/ctc.htm [last accessed 14 Feb. 2019].

[18] Bassi C, Marchegiani G, Dervenis C et al. The 2016 update of the International Study Group (ISGPS) definition and grading of postoperative pancreatic fistula: 11 Years After. Surgery. 2017 Mar;161(3):584-591.

[19] Wente MN, Bassi C, Dervenis C, et al. Delayed gastric emptying (DGE) after pancreatic surgery: a suggested definition by the International Study Group of Pancreatic Surgery (ISGPS). Surgery. 2007 Nov;142(5):761-8.

[20] Wente MN, Veit JA, Bassi C, et al. Post pancreatectomy hemorrhage (PPH): an International Study Group of Pancreatic Surgery (ISGPS) definition. Surgery 2007;142(1):205.

[21] Cella D, Butt Z, Kindler HL et al. Validity of the FACT Hepatobiliary (FACT-Hep) questionnaire for assessing disease-related symptoms and health-related quality of life in patients with metastatic pancreatic cancer. Qual Life Res. 2013; 22(5):1105-12.

[22] Carrato A, Falcone A, Ducreux M, et al. A systematic review of the burden of pancreatic cancer in Europe: real-world impact on survival, quality of life and costs. J Gastrointest Cancer. 2015 ; 46 :201-211. 


\section{VBHC Pancreas Set}

References

[23] Basch E, Deal AM, Dueck AC et al. Overall Survival Results of a Trial Assessing PatientReported Outcomes for Symptom Monitoring During Routine Cancer Treatment. JAMA.2017; 318(2):197-198.

[24] Desomer A, Van den Heede K, Triemstra M, Paget J, De Boer D, Kohn L, Cleemput I. L'utilisation des résultats et expériences rapportés par les patients (PROM/PREM) à des fins cliniques et de gestion - Synthèse. Health Services Research (HSR). Bruxelles : Centre Fédéral d'Expertise des Soins de Santé (KCE). 2018. KCE Reports 303Bs. D/2018/10.273/38. 
VBHC Pancreas Set

APPENDIX

Contributors (Delphi participants) \& Members of IHU-VBHC working group :

\begin{tabular}{|c|c|c|}
\hline Name & Expertise & Country \\
\hline Paulo AMARAL & HBP Surgeon & BRAZIL \\
\hline Catherine ANTHONY & Dietetician & FRANCE \\
\hline Raphael ARAUJO & HBP Surgeon & BRAZIL \\
\hline Horacio ASBUN & HBP Surgeon & USA \\
\hline Susan ATKINSON & Patient & USA \\
\hline Elena BANGOURA & Caregiver & FRANCE \\
\hline Marie-Pascale BATAILLE & Patient & FRANCE \\
\hline Kimberly BERTENS & HBP Surgeon & CANADA \\
\hline Sophie BLANĖS & Secretary & FRANCE \\
\hline Javier BRICENO & HBP Surgeon & SPAIN \\
\hline Hansen CARSTEN PALNAES & HBP Surgeon & DENMARK \\
\hline Maria CATALINA MURSCH & Nurse & FRANCE \\
\hline Clara CESARI-LOUSSOUARN & Psychologist & FRANCE \\
\hline Zineb CHERKAOUI & Resident in Digestive Surgery & FRANCE \\
\hline Natalie COBURN & HBP Surgeon & CANADA \\
\hline Fabrice COLIN & Patient & FRANCE \\
\hline Claudius CONRAD & HBP Surgeon & USA \\
\hline Vincent CORDELIER & Nurse & FRANCE \\
\hline Francis CREWS & Patient & FRANCE \\
\hline Vito DE BLASI & HBP Surgeon & LUXEMBOURG \\
\hline Gabrielle DEGUIO & Geriatrician & FRANCE \\
\hline Bastien DELATTRE & Consultant & FRANCE \\
\hline Nicolas DEMARTINES & HBP Surgeon & SWITZERLAND \\
\hline Kristine DENGSØ & Nurse & DENMARK \\
\hline Mark DOHERTY & Medical Oncologist & CANADA \\
\hline Elena FERNANDEZ & HBP Surgeon & FRANCE \\
\hline David FUKS & HBP Surgeon & FRANCE \\
\hline Armando GIL & HBP Surgeon & VENEZUELA \\
\hline Veronica GOLDBARG & Medical Oncologist & FRANCE \\
\hline Cristians GONZÁLEZ & Digestive Surgeon & VENEZUELA \\
\hline Elham HADDAD & Nurse & FRANCE \\
\hline Julie HALLET & HBP Surgeon & CANADA \\
\hline Nathalie HAUSSER & Nurse & FRANCE \\
\hline
\end{tabular}


VBHC Pancreas Set

Supplementary file

\begin{tabular}{|c|c|c|}
\hline Ruben HERNANDEZ & HBP Surgeon & VENEZUELA \\
\hline Hugo HERRSCHER & Medical Oncologist & FRANCE \\
\hline Ryota HIGUCHI & HBP Surgeon & JAPAN \\
\hline Jens HILLINGS $\varnothing$ & HBP Surgeon & DENMARK \\
\hline Paul HODY & Patient & FRANCE \\
\hline Pauline HORN & Dietetician & FRANCE \\
\hline Jerôme HUPPERTZ & Gastroenterologist & FRANCE \\
\hline Naoki IKARI & General surgeon & JAPAN \\
\hline Wataru IZUMO & HBP Surgeon & JAPAN \\
\hline Emilie JACKY & Nurse & FRANCE \\
\hline Shiva JAYARAMAN & HBP Surgeon & CANADA \\
\hline Romane JENNER & Dietetician & FRANCE \\
\hline Florence JEUNE & HBP Surgeon & FRANCE \\
\hline Hironori KANEKO & HBP Surgeon & JAPAN \\
\hline Takaaki KATO & HBP Surgeon & JAPAN \\
\hline Suneil KHANNA & Medical Oncologist & CANADA \\
\hline Sophie KIEFFER & Nurse & FRANCE \\
\hline Francine KLEIN & Head nurse & FRANCE \\
\hline Jean Emmanuel KURTZ & Medical Oncologist & FRANCE \\
\hline Calvin LAW & HBP Surgeon & CANADA \\
\hline Laura LAZARUS & Nurse & FRANCE \\
\hline Myriam LEKEIR & Nurse & FRANCE \\
\hline Elodie LÉOST & Patient-pathway Coordinator & FRANCE \\
\hline Bruno LEMOS & HBP Surgeon & BRAZIL \\
\hline Leonardo LIMA & HBP Surgeon & BRAZIL \\
\hline Constance LUGIEZ & Integrated Health Solutions Program Director & FRANCE \\
\hline Bernadette LUX & Patient & FRANCE \\
\hline Guilherme MACHADO & HBP Surgeon & BRAZIL \\
\hline Jacques MARESCAUX & Digestive Surgeon & FRANCE \\
\hline Guillaume MARTEL & HBP Surgeon & CANADA \\
\hline Lysiane MARTHEY & Medical Oncologist & FRANCE \\
\hline Pablo MARTÍ-CRUCHAGA & HBP Surgeon & SPAIN \\
\hline Elisa MARTINIS & Dietetician & FRANCE \\
\hline Riccardo MEMEO & HBP Surgeon & ITALY \\
\hline Jean-Michel MEYER & $\begin{array}{l}\text { Patient representative, } \\
\text { President of CISS-Alsace }\end{array}$ & FRANCE \\
\hline Lise MUNK PLUM & Nurse & DENMARK \\
\hline
\end{tabular}


VBHC Pancreas Set

Supplementary file

\begin{tabular}{|c|c|c|}
\hline Cesar MUNOZ & Medical Oncologist & SPAIN \\
\hline Didier MUTTER & Digestive Surgeon & FRANCE \\
\hline Sulaiman NANJI & HBP Surgeon & CANADA \\
\hline Amy O'CONNOR & Dietetician & CANADA \\
\hline Akiko OMORI & HBP Surgeon & JAPAN \\
\hline Pedro OSORIO & HBP Surgeon & BRAZIL \\
\hline Fabrizio PANARO & HBP Surgeon & FRANCE \\
\hline Fernando PARDO & HBP Surgeon & SPAIN \\
\hline Lucio Lucas PEREIRA & HBP Surgeon & BRAZIL \\
\hline Pierre PEREZ & Patient & FRANCE \\
\hline Sophie PERNOT & Preclinical \& innovation project manager & FRANCE \\
\hline Patrick PESSAUX & HBP Surgeon & FRANCE \\
\hline Yolanda QUIJANO & HBP Surgeon & SPAIN \\
\hline Mariana RAMALLO & Psychiatrist & VENEZUELA \\
\hline Nicolas REGENET & HBP Surgeon & FRANCE \\
\hline Alexandre RESENDE & HBP Surgeon & BRAZIL \\
\hline Fernando ROTELLAR & HBP Surgeon & SPAIN \\
\hline Antonio SA CUNHA & HBP Surgeon & FRANCE \\
\hline Rodrigo SANCHEZ CLARIA & HBP Surgeon & ARGENTINA \\
\hline Daniel SANTANA & HBP Surgeon & BRAZIL \\
\hline Rodolfo SANTANA & HBP Surgeon & BRAZIL \\
\hline Alain SCHAFF & Patient & FRANCE \\
\hline Lilian SCHWARZ & HBP Surgeon & FRANCE \\
\hline Maja SEGEDI & HBP Surgeon & CANADA \\
\hline Sébastien SERRA & Medical Oncologist & FRANCE \\
\hline Pablo SERRANO & HBP Surgeon & CANADA \\
\hline Masahiro SHIIHARA & HBP Surgeon & JAPAN \\
\hline Olivier SOUBRANE & HBP Surgeon & FRANCE \\
\hline Marie STÉPHAN & Nurse & FRANCE \\
\hline Nobuhiro TAKESHITA & Medical Oncologist & JAPAN \\
\hline Orlando TORRES & HBP Surgeon & BRAZIL \\
\hline Melanie TSANG & HBP Surgeon & CANADA \\
\hline Olivier TURRINI & HBP Surgeon & FRANCE \\
\hline Shuichiro UEMURA & HBP Surgeon & JAPAN \\
\hline Eliana VALLE & Radiologist & BRAZIL \\
\hline Anna VAN OSCH & Dietetician & CANADA \\
\hline Emilio VICENTE & HBP Surgeon & SPAIN \\
\hline
\end{tabular}


VBHC Pancreas Set

Supplementary file

\begin{tabular}{|l|l|l|}
\hline Annie VINCENT & Patient & FRANCE \\
\hline Go WAKABAYASHI & HBP Surgeon & JAPAN \\
\hline Taiga WAKABAYASHI & HBP Surgeon & JAPAN \\
\hline Helmut WEISS & HBP Surgeon & AUSTRIA \\
\hline Masakazu YAMAMOTO & HBP Surgeon & JAPAN \\
\hline Shingo YAMASHITA & HBP Surgeon & JAPAN \\
\hline Takehisa YAZAWA & HBP Surgeon & JAPAN \\
\hline Thomas ZACHARIAS & HBP Surgeon & FRANCE \\
\hline
\end{tabular}

